\title{
Vaping-Linked Lung Disease: Implication for Pro-oxidant Effect of Vitamin E
}

\author{
Stanley T Omaye* \\ Department of Nutrition and Environmental Sciences Graduate Program, University of Nevada, USA
}

*Corresponding author: Stanley T Omaye, Department of Nutrition and Environmental Sciences Graduate Program, University of Nevada, USA

\section{ARTICLE INFO}

Received: 业 December 07, 2019

Published: 幽 December 12, 2019

Citation: Stanley T Omaye. Vaping-Linked Lung Disease: Implication for Pro-oxidant Effect of Vitamin E. Biomed J Sci \& Tech Res 23(5)-2019. BJSTR. MS.ID.003962.

\section{ABSTRACT}

Vaporing products have been purported to be complemented with vitamin E acetate presumed for the chemical antioxidant role. However, we speculate that the direct deposition of vitamin E compounds to lung tissues can result in pro-oxidant effects resulting in promoting oxidation of cellular lipids and damage to biological constituents, such as; protein, carbohydrates, and DNA. Subsequently, the use of vitamin E in vaporing products may lead to acute or chronic lung damage.

Keywords: Vaporing; Vitamin E; Pro-oxidants; Antioxidants; High oxygen tension; Phospholipids

\section{Introduction}

Vitamin E or chemical derivative, such as; tocopheryl acetate, is found in many supplements or cosmetics. Recently vitamin $\mathrm{E}$ has been suggested to be connected with serious lung disorders caused by vaping [1]. The major function of vitamin $\mathrm{E}$ is as an antioxidant. The essence of the antioxidant hypothesis for protection against chronic diseases is that these compounds will protect the organism against adverse oxidative effects without inhibiting the positive benefits of oxygen use [2]. Ironically and occasionally ignored is under certain physiological conditions, antioxidants can exhibit adverse effects. Many antioxidants have been observed to exhibited pro-oxidant effects because of their structure, high oxygen tension, presence of metal ions, high concentrations of antioxidant compounds, and temperature [3]. Therefore, the direct instillation of vitamin $\mathrm{E}$ that would occur by vaporing likely represents an ideal environment for the initiation of pro-oxidant attributes.

\section{Discussion}

Due to the ability to donate phenolic hydrogen of the chromanol ring at the position 6 to lipid-free radicals, tocopherols and tocotrienols exhibit antioxidant activity (Figure 1). As an antioxidant, tocopherols and tocotrienols protect tissue lipids from free radicals. Vitamin E compound is the primary chain-breaking antioxidant in membranes and lipoproteins and, as such, reduces chemical species such as peroxyl, hydroxyl, and superoxide radicals and singlet oxygen. Vitamin E has been often referred to as Nature's best chain-breaking antioxidant. Typically, one molecule of the vitamin protects about 100 membrane phospholipids [4]. Ideally, effective antioxidants should yield radicals that are unreactive toward stable molecules, and that results in limiting their reactions only to the donation of hydrogens to radicals. In vivo, vitamin E and other endogenous antioxidants work in concert or synergistically maintaining a reduced environment (Figure 2). However, antioxidants and their radicals often undergo other side reactions that may be classified as pro-oxidant $[5,6]$.

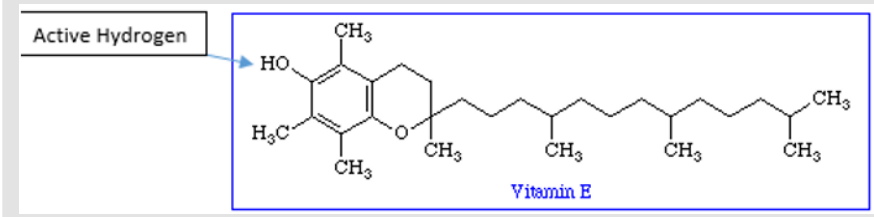

Figure 1: Chemical structure of Vitamin E, illustrating active hydrogen for scavenging free radicals [4]. 


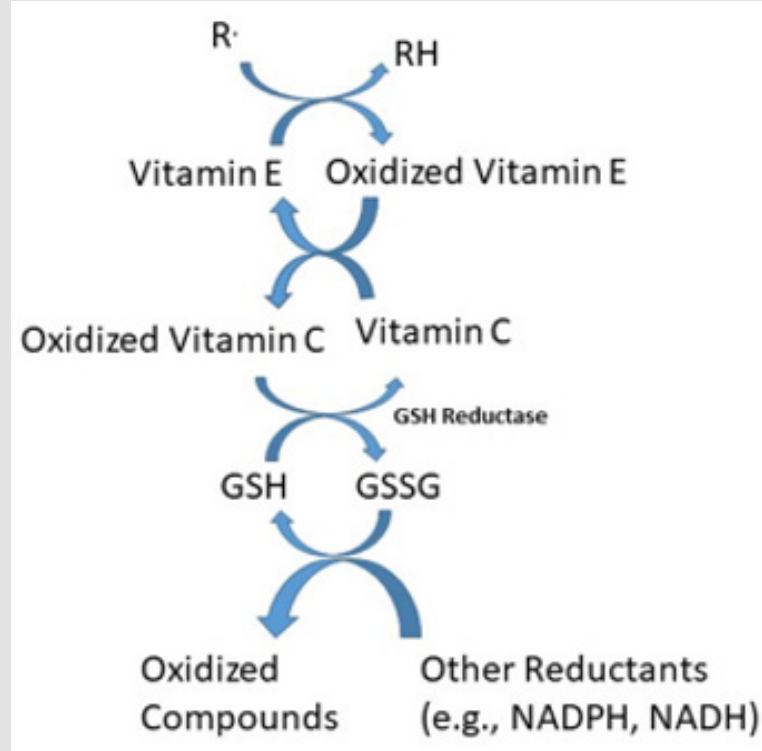

Figure 2: The synergistic relationship between vitamin E, C, and glutathione (GSH). Radical (R.), Reduced compound (RH), oxidized glutathione (GSSG) [2].

There is a potential for vitamin E compounds to act as pro-oxidants, particularly the tocopheroxyl radical [7]. When the concentration of tocopheroxyl radical is high enough, it is possible for several undesirable side reactions to occur, which in turn may initiate a chain reaction enhancing lipid peroxidation. In suspensions of low-density lipoproteins isolated from blood, vitamin $\mathrm{E}$ can accelerate the peroxidation of polyunsaturated fatty acids [2]. Food scientists have known about a similar situation in

\section{ISSN: 2574-1241}

DOI: 10.26717/BJSTR.2019.23.003962

Stanley T Omaye. Biomed J Sci \& Tech Res

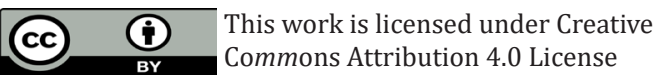

Submission Link: https://biomedres.us/submit-manuscript.php the food industry. Oxidation of food vegetable oils can occur when the vitamin E content becomes greater than 2,000 ppm.

\section{Conclusion}

Inhalation of vitamin E via vaporing is contraindicated. The lung is under high oxygen tension and presents an ideal environment for vitamin $\mathrm{E}$ to exhibit pro-oxidant effects. Recent cases of related lung damage to vaporing may be related to pro-oxidant effects of vitamin $\mathrm{E}$ added to vaporing products.

\section{Acknowledgment}

None.

\section{Conflict of Interest}

No conflict of interest.

\section{References}

1. Trager R (2019) Death from vaping-linked lung disease in US connected to vitamin $\mathrm{E}$ additive. Chemistry World.

2. Omaye ST, Zhang, P (2001) beta-Carotene: interactions with alphatocopherol and ascorbic acid in microsomal lipid peroxidation. J Nutr Biochem 12(1): 38-45.

3. Omaye ST (1999) Safety facets of antioxidant supplements. Topics in Clin Nutr 14(1): 26-41.

4. Tappel AL (1973) Vitamin E. Nutr Today 8: 4-12.

5. Zhang P, Omaye T (2001) Antioxidant and prooxidant roles for betacarotene, alpha-tocopherol and ascorbic acid in human lung cells. Toxicology in Vitro 15(1): 13-24.

6. Zhang P, Omaye ST (2001) DNA strand breakage and oxygen tension: Effects of beta-carotene, alpha-tocopherol, and ascorbic acid. Food Chem Toxicol 39(3): 239-246.

7. Pokorny J (1987) Major factors affecting the autoxidation of lipids. In Autoxidation of Unsaturated lipid.

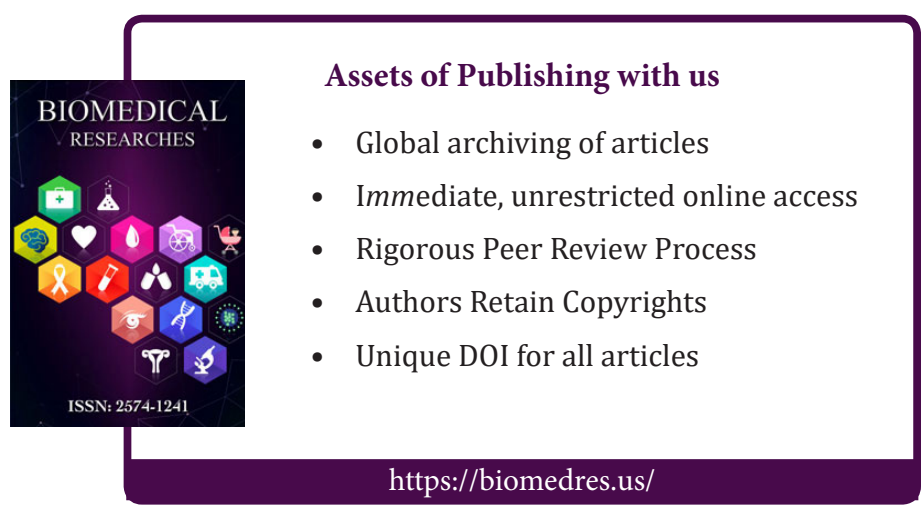

